\title{
NOTES
}

\section{Chromatographic Application of 3,4-Di-O-alkyl-(1 $\rightarrow$ 6)-2,5-anhydro-D-glucitol for Separation of Alkali and Alkaline Earth Metal Ions}

\author{
Toshifumi SAtoh,,${ }^{1,2}$ Issei OTsuka, ${ }^{1}$ Ryosuke SaKai,,${ }^{1}$ Kei SaItoh, ${ }^{1}$ \\ Satoshi Umeda, ${ }^{3}$ Katsuyuki Tsuda,${ }^{3}$ Hisaho Hashimoto, ${ }^{4},{ }^{1}$ and Toyoji KaKuCHI ${ }^{1, \dagger}$ \\ ${ }^{1}$ Division of Biotechnology and Macromolecular Chemistry, Graduate School of Engineering, \\ Hokkaido University, Sapporo 060-8628, Japan \\ ${ }^{2}$ Division of Innovative Research, Creative Research Initiative "Sousei” (CRIS), \\ Hokkaido University, Sapporo 001-0021, Japan \\ ${ }^{3}$ Department of Material Chemistry, Asahikawa National College of Technology, \\ Asahikawa 071-8142, Japan \\ ${ }^{4}$ Department of Science and Engineering for Materials, Tomakomai National College \\ of Technology, Tomakomai 059-1275, Japan
}

(Received November 2, 2005; Accepted January 4, 2006; Published May 15, 2006)

KEY WORDS Macromolecular Ionophore / Chromatographic Separation / Metal Cation-selectivity / Molecular Recognition / [doi:10.1295/polymj.38.490]

In host-guest chemistry, polyether antibiotics, such as monensin and nigericin consisting of a formally linear array of tetrahydrofuranyl and tetrahydropyranyl rings, are known as ionophores, which form a lipophilic complex with cations and transport the cations across the membrane by ion complex-decomplex formation. During the molecular recognition, the conformation of the ionophore changes from an acyclic to pseudocyclic structure by forming a complex with appropriate metal cation. Thus, of great interest is the design, synthesis, and characterization of macromolecular ionophores from the viewpoint of the development of an acyclic host. Previously, it was reported that poly(cyclooxalkane)diyl ${ }^{1}$ and poly(7oxanorbornene $)^{2}$ were synthesized as macromolecular ionophores, which were supposed to form helical conformers capable of varying the pitch and cavity size to optimize the multidentate coordination with a given cation. In addition, we established the cyclopolymerization of a dianhydro sugar leading to novel carbohydrate polymers as macromolecular ionophores, ${ }^{3}$ in particular, 3,4-di- $O$-alkyl-(1 $\rightarrow 6)$-2,5-anhydro-D-glucitol (1; alkyl = ethyl (1a), methyl (1b), allyl (1c)), which was synthesized by the regio- and stereoselective cyclopolymerization of 3,4-di-O-alkyl-1,2:5,6dianhydro-D-mannitol, exhibited versatile molecular recognition characteristics, such as the metal cationselectivity and chiral discrimination ability. ${ }^{4-13}$ In or-

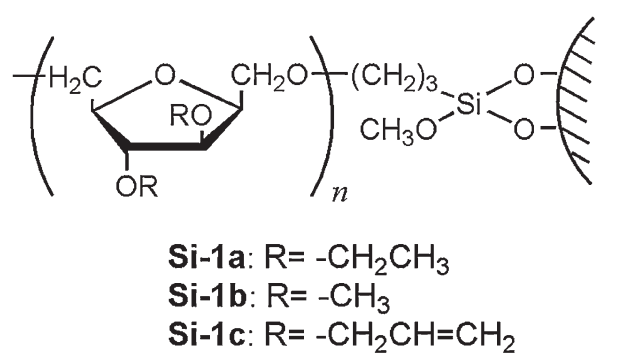

Figure 1. 3,4-Di-O-alkyl-(1 $\rightarrow$ 6)-2,5-anhydro-D-glucitol bound on silica gel (Si-1a-c).

der to utilize the molecular recognition property of $\mathbf{1}$, we prepared and examined the 1-bound silica gel (Si-1) as chiral stationary phase in HPLC for resolving racemic amines, amino acids, and amino esters. ${ }^{14-16}$ Thus we now report the chromatographic separation of alkali and alkaline earth metal halides by columns packed with 1-bound silica gels (alkyl: ethyl, Si-1a; methyl, Si-1b; allyl, Si-1c) using direct and indirect detection methods by HPLC (Figure 1). The liquidliquid extraction property of 1a toward alkali metal picrates is compared in order to characterize the chromatographic separation property of $\mathbf{1}$ using the direct detection method. In addition, we discuss the effect of the eluent on the chromatographic separation of metal cations.

${ }^{\dagger}$ To whom correspondence should be addressed (Tel: +81-11-706-6602, Fax: +81-11-706-6602, E-mail: kakuchi@poly-bm.eng.hokudai.ac.jp). 


\section{EXPERIMENTAL}

\section{Materials}

Analytical grade alkali, alkaline earth, and transition metal chlorides were purchased from the Kanto Chemical Co., Japan. The polymers bound on silica gel $(\mathbf{S i}-\mathbf{1 a}-\mathbf{c})$ were prepared using a method that were reported in a previous paper, and packed in a stainless-steel tube $(20 \times 0.6 \mathrm{~cm}$ i.d. $)$ at $250 \mathrm{~kg} \cdot \mathrm{cm}^{-2}$ by the slurry method using carbon tetrachloride. ${ }^{16} \mathrm{Col}-$ umn Si-1a: the polymer with the number-averaged molecular weight $\left(M_{\mathrm{n}}\right)$ of 3100 and the polydispersity $\left(M_{\mathrm{w}} / M_{\mathrm{n}}\right)$ of 1.60 was used. Anal. C, $15.5 \%$. The number of theoretical plates was about 11000 for phenylglycine. Column Si-1b: the polymer with the $M_{\mathrm{n}}$ of 2700 and the $M_{\mathrm{w}} / M_{\mathrm{n}}$ of 1.45 was used. Anal. C, $14.4 \%$. The number of theoretical plates was about 9200 for phenylglycine. Column Si-1c: the polymer with the $M_{\mathrm{n}}$ of 3900 and the $M_{\mathrm{w}} / M_{\mathrm{n}}$ of 1.60 was used. Anal. C, $15.3 \%$. The number of theoretical plates was about 10800 for phenylglycine.

\section{Extraction Measurement}

Liquid-liquid extraction of alkali metal picrates with (1 $\rightarrow$ 6)-2,5-anhydro-3,4-di- $O$-ethyl-D-glucitol (1a) was carried out using the same conditions that were reported in previous papers. ${ }^{12}$ The polymer was obtained from 1,2:5,6-dianhydro-3,4-di- $O$-ethyl-D-mannitol using $t$-BuOK and its $M_{\mathrm{n}}$ was $3100\left(M_{\mathrm{w}} / M_{\mathrm{n}}\right.$, $1.60)$.

\section{Ion Chromatography}

The ion chromatographic experiments for the separation of metal cations were performed by two methods, a direct detection method by a conductivity measurement using a Shimadzu CDD-6A detector and an indirect detection by a UV measurement at $225 \mathrm{~nm}$ using a Jasco UV-975 detector. The eluents used were aqueous solutions $\left(2.0 \mathrm{mmol} \cdot \mathrm{L}^{-1}\right)$ of nitric acid, hydrochloric acid, perchloric acid, and potassium hydrogen phthalate for the direct detection method and an aqueous copper (II) sulfate solution $\left(2.5 \mathrm{mmol} \cdot \mathrm{L}^{-1}\right)$ for the indirect detection method. The eluents were filtered through a $1.0 \mu \mathrm{m}$ membrane filter before use. $20 \mu \mathrm{L}$ samples were injected into the HPLC system. The flow rate was $1.0 \mathrm{~mL} \cdot \mathrm{min}^{-1}$ and the temperature was $22^{\circ} \mathrm{C}$.

\section{RESULTS AND DISCUSSION}

The separation ability of the $(1 \rightarrow 6)-2,5$-anhydro3,4-di-O-ethyl-D-glucitol-bound silica gel (Si-1a) toward alkali metal chlorides was evaluated by a direct detection method with a conductivity detector and an



Figure 2. Chromatographic separation of alkaline metal chloride on Si-1a. A) Direct detection method using $2.0 \mathrm{mmol} \cdot \mathrm{L}^{-1}$ aqueous $\mathrm{HNO}_{3}$ solution; B) Indirect detection method using 2.5 $\mathrm{mmol} \cdot \mathrm{L}^{-1}$ aqueous $\mathrm{CuSO}_{4}$ solution; flow rate, $1.0 \mathrm{~mL} \cdot \mathrm{min}^{-1}$; sample concentration: $\mathrm{Li}^{+}, 0.5 \mathrm{ppm} ; \mathrm{Na}^{+}, 2.5 \mathrm{ppm} ; \mathrm{K}^{+}, 10 \mathrm{ppm}$; $\mathrm{Rb}^{+}, 30 \mathrm{ppm} ; \mathrm{Cs}^{+}, 60 \mathrm{ppm}$.

indirect detection method with a UV detector at $225 \mathrm{~nm}$. Figure 2 shows the chromatographic results of the stationary phase, Si-1a. When nitric acid was used as the mobile phase for the direct detection method, the separation of alkali metal chlorides was observed. The retention time increased with the increasing radius of the alkali metal cations as $\mathrm{Li}^{+}<\mathrm{Na}^{+}<$ $\mathrm{K}^{+}<\mathrm{Rb}^{+}<\mathrm{Cs}^{+}$(Figure 2A). On the other hand, for the indirect detection method with an aqueous copper (II) sulfate solution, all the metal cations were eluted within $20 \mathrm{~min}$ and the partial separation of alkali metal cations is observed, as shown in Figure 2B. Table I summarizes the capacity factor $\left(k^{\prime}\right)$ and the separation factors $(\alpha)$, using the direct and indirect detection methods. The separation results using the direct detection method are better than those using the indirect detection method, indicating that the low separation property for the indirect detection method may be caused by the low exchange rate between the alkali metal cation and $\mathrm{Cu}^{2+}$ on the polymer, $\mathbf{1 a}$.

Previously, we reported the molecular recognition property of 1a-c as the macromolecular ionophore, using a liquid-liquid extraction method. Thus, in or- 
T. SАTOH et al.

Table I. Chromatographic separation of alkali metal chloride using Si-1a ${ }^{\mathrm{a}}$

\begin{tabular}{cccccc}
\hline \multirow{2}{*}{ Alkali metal cation } & \multicolumn{2}{c}{ Direct detection method } & & \multicolumn{2}{c}{ Indirect detection method $^{\mathrm{c}}$} \\
\cline { 2 - 3 } \cline { 5 - 6 } & $k^{\prime \mathrm{d}}$ & $\alpha^{\mathrm{e}}$ & & $k^{\prime \mathrm{d}}$ & $\alpha^{\mathrm{e}}$ \\
\hline $\mathrm{Li}^{+}$ & 1.89 & 3.84 & & 1.52 & 1.68 \\
$\mathrm{Na}^{+}$ & 2.19 & 3.32 & & 1.76 & 1.45 \\
$\mathrm{~K}^{+}$ & 4.03 & 1.80 & & 2.13 & 1.20 \\
$\mathrm{Rb}^{+}$ & 5.14 & 1.41 & & 2.25 & 1.14 \\
$\mathrm{Cs}^{+}$ & 7.26 & - & & 2.56 & - \\
\hline
\end{tabular}


$60 \mathrm{ppm}$. ${ }^{\mathrm{b}}$ Eluent, $2.0 \mathrm{mmol} \cdot \mathrm{L}^{-1} \mathrm{HNO}_{3}$. ${ }^{\mathrm{c}}$ Eluent, $2.5 \mathrm{mmol} \cdot \mathrm{L}^{-1}$ aqueous $\mathrm{CuSO}_{4}$ solution. ${ }^{\mathrm{d}}$ Capacity factor: $k_{\mathrm{Li}}^{\prime}=\left(\mathrm{t}_{\mathrm{Li}}-\mathrm{t}_{0}\right) / \mathrm{t}_{0}$. ${ }^{\mathrm{d}}$ Separation factor of $\mathrm{Li}^{+}, \mathrm{Na}^{+}, \mathrm{K}^{+}$, and $\mathrm{Rb}^{+}$over $\mathrm{Cs}^{+}$: for example, $\alpha_{\mathrm{Li}}=k_{\mathrm{Cs}}^{\prime} / k_{\mathrm{Li}}^{\prime}$.

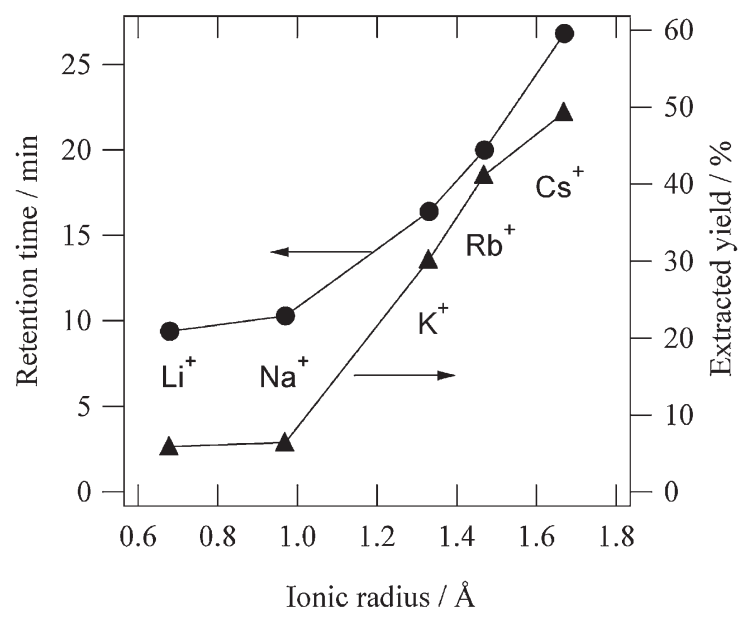

Figure 3. Plots of the retention time and extraction yield $v s$. the ionic radius of alkali metal cations. Chromatographic separation (closed circle) was attained by $\mathbf{S i - 1 a}$ using $2.0 \mathrm{mmol} \cdot \mathrm{L}^{-1}$ aqueous $\mathrm{HNO}_{3}$ solution as the eluent. The extraction of the alkali metal picrate by $1 \mathrm{a}$ (closed triangle) was carried out at $20^{\circ} \mathrm{C}$ using an organic phase $(2.5 \mathrm{~mL})$ including 5.75 repeating unitsmmol. $\mathrm{L}^{-1}$ 1a solution $\left(\mathrm{CH}_{2} \mathrm{Cl}_{2}\right)$ and water phase $(2.5 \mathrm{~mL})$ including $10.0 \mathrm{mmol} \cdot \mathrm{L}^{-1}$ alkali metal chloride and $7.00 \times 10^{-2}$ $\mathrm{mmol} \cdot \mathrm{L}^{-1}$ picric acid.

der to characterize the chromatographic separation property of 1a-c using the direct detection method, the results using the liquid-liquid extraction method for alkali metal picrates is represented in Figure 3. The solvent extractions of alkali metal picrates using the water-dichloromethane solvent system were carried out using $(1 \rightarrow 6)$-2,5-anhydro-3,4-di- $O$-ethyl-Dglucitol 1a $\left(M_{\mathrm{n}}=3100\right.$ and $\left.M_{\mathrm{w}} / M_{\mathrm{n}}=1.60\right)$. The extraction yield increased in the order of $\mathrm{Li}^{+}<\mathrm{Na}^{+}$ $\ll \mathrm{K}^{+}<\mathrm{Rb}^{+}<\mathrm{Cs}^{+}$, which should be caused by the fact that the conformer of $\mathbf{1 a}$ varied its pitch and cavity size for forming a complex with a given metal cation, this is, the character of 1a as a macromolecular ionophore. The results for the liquid-liquid extraction experiment were very similar to the order of the retention time for the ion chromatographic experiment, indicating that the elution order of alkali metal cations for the chromatographic separation is dependent on

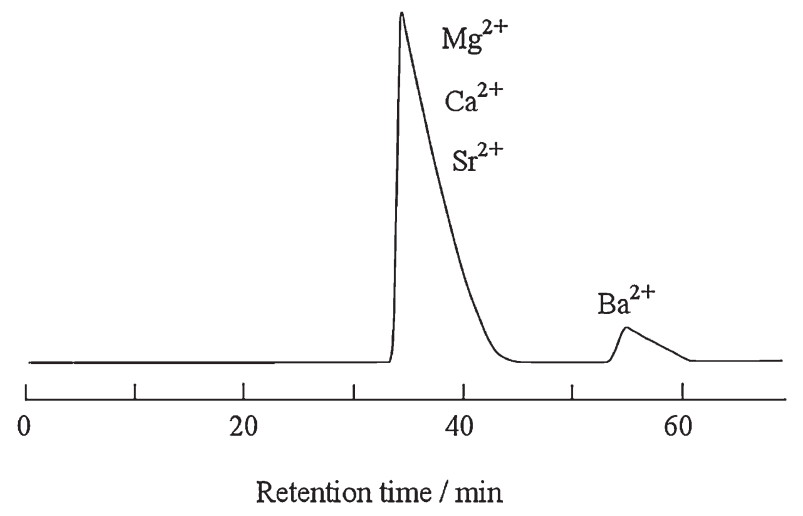

Figure 4. Chromatographic separation of alkali earth metal chloride on Si-1a. Eluent, $2.0 \mathrm{mmol} \cdot \mathrm{L}^{-1} \mathrm{HNO}_{3}$; Flow rate, 1.0 $\mathrm{mL} \cdot \mathrm{min}^{-1}$; Sample concentration: $\mathrm{Mg}^{2+}, 10 \mathrm{ppm}$; $\mathrm{Ca}^{2+}, 10 \mathrm{ppm}$; $\mathrm{Sr}^{2+}, 20 \mathrm{ppm} ; \mathrm{Ba}^{2+}, 30 \mathrm{ppm}$.

the characteristic of the macromolecular ionophore 1a possessing the cation-selectivity toward alkali metal ions.

Figure 4 shows the separation results for alkaline earth chlorides using $\mathbf{S i - 1 a}$. The separation of $\mathrm{Ba}^{2+}$ vs. $\mathrm{Mg}^{2+}, \mathrm{Ca}^{2+}$, and $\mathrm{Sr}^{2+}$ is observed. The non-selectivity for $\mathrm{Mg}^{2+}, \mathrm{Ca}^{2+}$, and $\mathrm{Sr}^{2+}$ should be due to the small cation radius. Thus, the low extractability for cation having radii below $1.2 \AA$ resulted from the liquid-liquid extraction using polymer $\mathbf{1 b},{ }^{12}$ meaning that the $\mathrm{Mg}^{2+}, \mathrm{Ca}^{2+}$, and $\mathrm{Sr}^{2+}$ ions were too small to fit the cavity in polymer 1a. The non-selectivity for $\mathrm{Ni}^{2+}, \mathrm{Co}^{2+}$, and $\mathrm{Cu}^{2+}$ having a small radius was also observed by the direct detection method.

Chromatographic experiments using hydrochloric acid, perchloric acid, and an aqueous potassium hydrogen phthalate solution were carried out to determine the effect of eluent on the separation of alkali metal cations. Figure 5 shows the chromatographic results. All the experiments show partial separations of the alkali metal ions and the elution order was the same as that using nitric acid. The retention time for $\mathrm{Li}^{+}$increased in the order of hydrochloric acid, perchloric acid, nitric acid and potassium hydrogen phthalate. For the potassium hydrogen phthalate solu- 

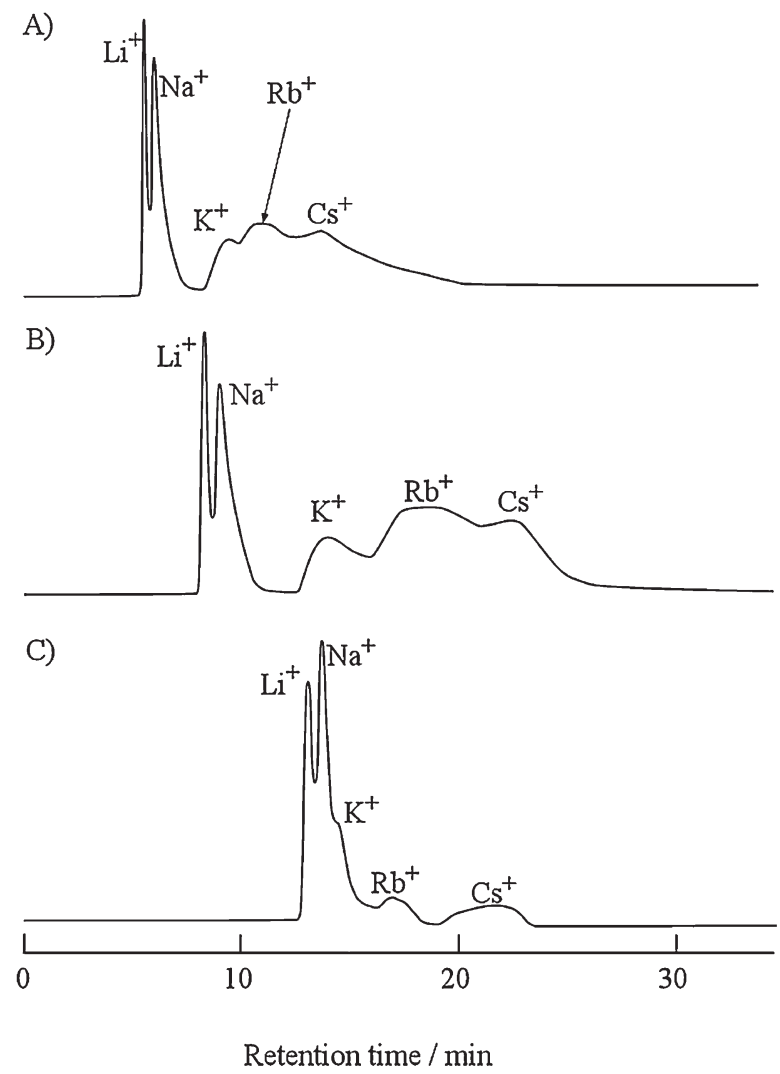

Figure 5. Chromatographic separation of alkali metal chloride on Si-1a. Eluent: A) $2.0 \mathrm{mmol} \cdot \mathrm{L}^{-1}$ hydrochloric acid; B) $2.0 \mathrm{mmol} \cdot \mathrm{L}^{-1}$ aqueous $\mathrm{HClO}_{4}$ solution; C) $2.0 \mathrm{mmol} \cdot \mathrm{L}^{-1}$ aqueous potassium hydrogen phthalate solution; flow rate, $1.0 \mathrm{~mL} \cdot \mathrm{min}^{-1}$; sample concentration: $\mathrm{Li}^{+}, 0.5 \mathrm{ppm} ; \mathrm{Na}^{+}, 2.5 \mathrm{ppm} ; \mathrm{K}^{+}, 10 \mathrm{ppm}$; $\mathrm{Rb}^{+}, 30 \mathrm{ppm} ; \mathrm{Cs}^{+}, 60 \mathrm{ppm}$.

tion, there was little difference in the chromatographic results regarding the non-separation for $\mathrm{Na}^{+}$and $\mathrm{K}^{+}$ and the separation for $\mathrm{Rb}^{+}$and $\mathrm{Cs}^{+}$. With 2.0 $\mathrm{mmol} \cdot \mathrm{L}^{-1}$ acetic acid as the eluent, the non-selectivity of all the alkali metal cations was observed. These results indicate that there is an eluent dependence for the cation selectivity.

In order to improve the cation selectivity, the addition of an organic solvent to the aqueous perchloric acid solution is shown in Figure 6. The addition of acetonitrile increases the binding constants between the cation and polymer by reducing the competition of solvent molecules for the cations. Thus when acetonitrile is present in the eluent, the cations are retained longer on column Si-1a than when an aqueous perchloric acid is used. As shown in Figure 6, the increasing percentage of acetonitrile in the eluent increased the retention times and thus yielded a better separation for the $\mathrm{Li}^{+}, \mathrm{Na}^{+}$, and $\mathrm{K}^{+}$peaks. The addition of methanol to the aqueous perchloric acid was also effective for the separation. Therefore, the chromatographic separation can be controlled by the addition of an organic solvent to the mobile phase in the system.

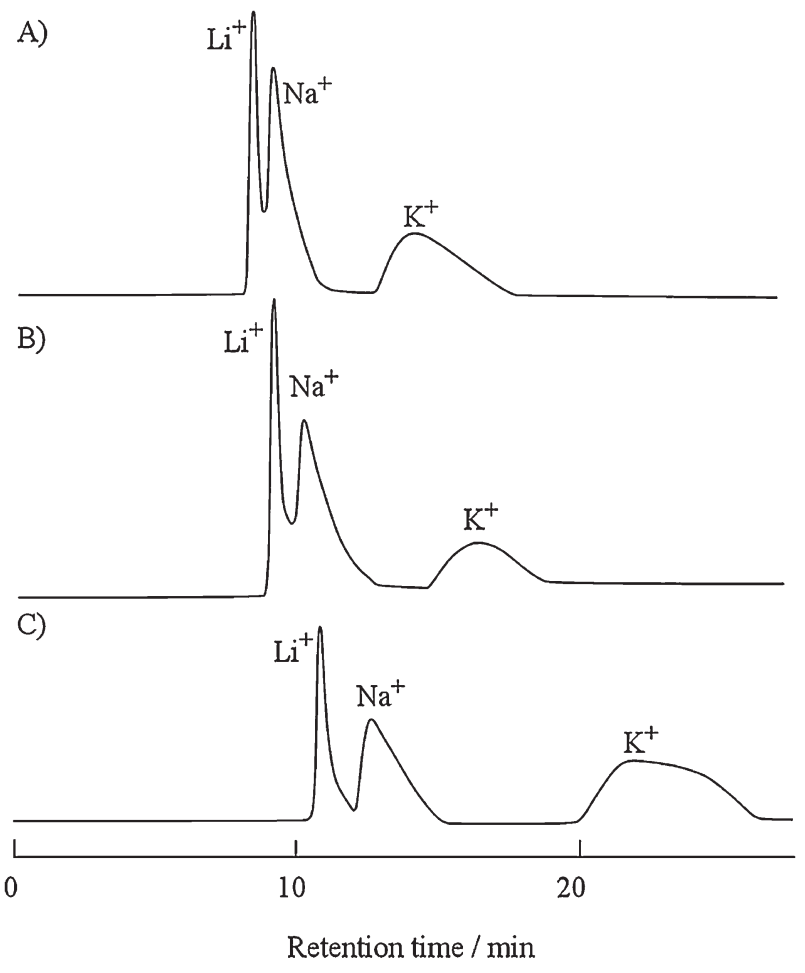

Figure 6. Effect of $\mathrm{CH}_{3} \mathrm{CN}$ on elution of $\mathrm{Li}^{+}, \mathrm{Na}^{+}$, and $\mathrm{K}^{+}$. Eluent: A) $2.0 \mathrm{mmol} \cdot \mathrm{L}^{-1}$ aqueous $\mathrm{HClO}_{4}$ solution; B) 2.0 mmol. $\mathrm{L}^{-1}$ aqueous $\mathrm{HClO}_{4}$ solution $/ \mathrm{CH}_{3} \mathrm{CN}(\mathrm{v} / \mathrm{v}, 9 / 1)$; C) 2.0 $\mathrm{mmol} \cdot \mathrm{L}^{-1}$ aqueous $\mathrm{HClO}_{4}$ solution $/ \mathrm{CH}_{3} \mathrm{CN}(\mathrm{v} / \mathrm{v}, 7 / 3)$; flow rate, $1.0 \mathrm{~mL} \cdot \mathrm{min}^{-1}$; sample concentration: $\mathrm{Li}^{+}, 0.5 \mathrm{ppm} ; \mathrm{Na}^{+}, 2.5 \mathrm{ppm}$; $\mathrm{K}^{+}, 10$ ppm.

In order to elucidate the effect of the 3,4-substituents of 1a-c on the ion chromatography, 3,4-di-Omethyl- and 3,4-di- $O$-allyl-( $1 \rightarrow 6)$-2,5-anhydro-D-glucitol-bound silica gels (Si-1b and $\mathbf{S i - 1 c}$, respectively) are used for the cation selectivity of the alkali and alkaline earth metal chlorides (Figures 7 and 8). For the separation of alkali metal cations using $\mathbf{S i - 1} \mathbf{1 b}$, the retention time and selectivity for each cation are very similar to those using Si-1a. On the other hand, the retention times for all cations using Si-1c are shorter than those using $\mathbf{S i - 1 a}$, and the separation for $\mathrm{K}^{+}$, $\mathrm{Rb}^{+}$, and $\mathrm{Cs}^{+}$using $\mathbf{S i - 1 c}$ is better than that using Si-1a. For the separation of alkaline earth metal cations, the retention time of each cation decreased with the increasing hydrophobic property of the 3,4-substituents in the order of Si-1c $<$ Si-1a $<$ Si-1b. These columns could not be used to separate $\mathrm{Mg}^{2+}, \mathrm{Ca}^{2+}$, and $\mathrm{Sr}^{2+}$. The increasing hydrophobic property of a polymer led to a decreased retention time, and the change in the cavity of the polymer should improve the selectivity of each cation.

\section{CONCLUSIONS}

The chromatographic separation of alkali and alkaline earth metal halides was achieved using columns 

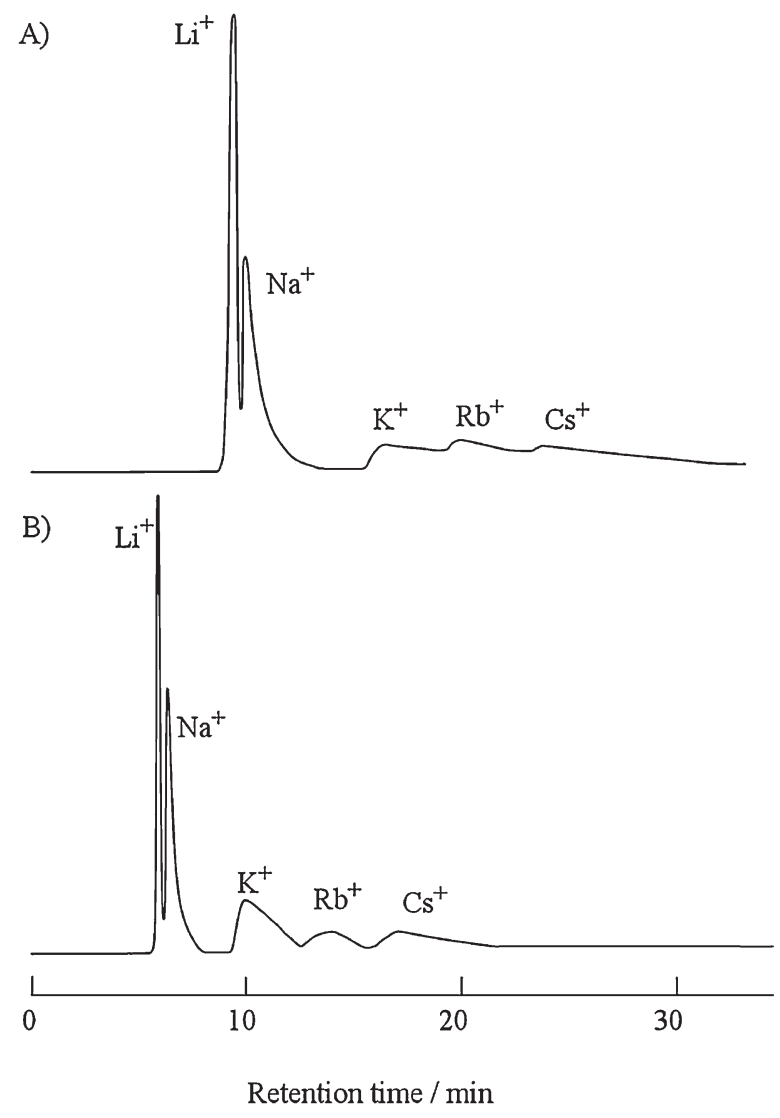

Figure 7. Chromatographic separation of alkali metal chloride on A) Si-1b and B) Si-1c. Eluent, $2.0 \mathrm{mmol} \cdot \mathrm{L}^{-1} \mathrm{HNO}_{3}$; flow rate, $1.0 \mathrm{~mL} \cdot \mathrm{min}^{-1}$; sample concentration: $\mathrm{Li}^{+}, 0.5 \mathrm{ppm} ; \mathrm{Na}^{+}$, $2.5 \mathrm{ppm} ; \mathrm{K}^{+}, 10 \mathrm{ppm} ; \mathrm{Rb}^{+}, 30 \mathrm{ppm} ; \mathrm{Cs}^{+}, 60 \mathrm{ppm}$.

packed with 3,4-di- $O$-alkyl-(1 $\rightarrow 6)$-2,5-anhydro-Dglucitol bound on silica gels (alkyl: ethyl (Si-1a), methyl (Si-1b), allyl (Si-1c)). When nitric acid was used as the mobile phase, silica gels $\mathbf{S i - 1 a - c}$ provided the good separation of alkali metal chlorides and the order of elution was $\mathrm{Li}^{+}<\mathrm{Na}^{+} \ll \mathrm{K}^{+}<\mathrm{Rb}^{+}<$ $\mathrm{Cs}^{+}$. The chromatographic separation was controlled by addition of an organic solvent to the mobile phase in the system. Thus, silica gel Si-1a-c can be used as the chromatographic stationary phase for resolving metal cations as well as racemic compounds.

\section{REFERENCES}

1. W. J. Schultz, M. C. Etter, A. V. Pocius, and S. Smith, J. Am. Chem. Soc., 102, 7981 (1980).

2. B. M. Novak and R. H. Grubbs, J. Am. Chem. Soc., 110, 960 (1988).

3. T. Satoh and T. Kakuchi, Prog. Polym. Sci., 29, 13 (2004).

4. H. Hashimoto, T. Kakuchi, and K. Yokota, J. Org. Chem.,

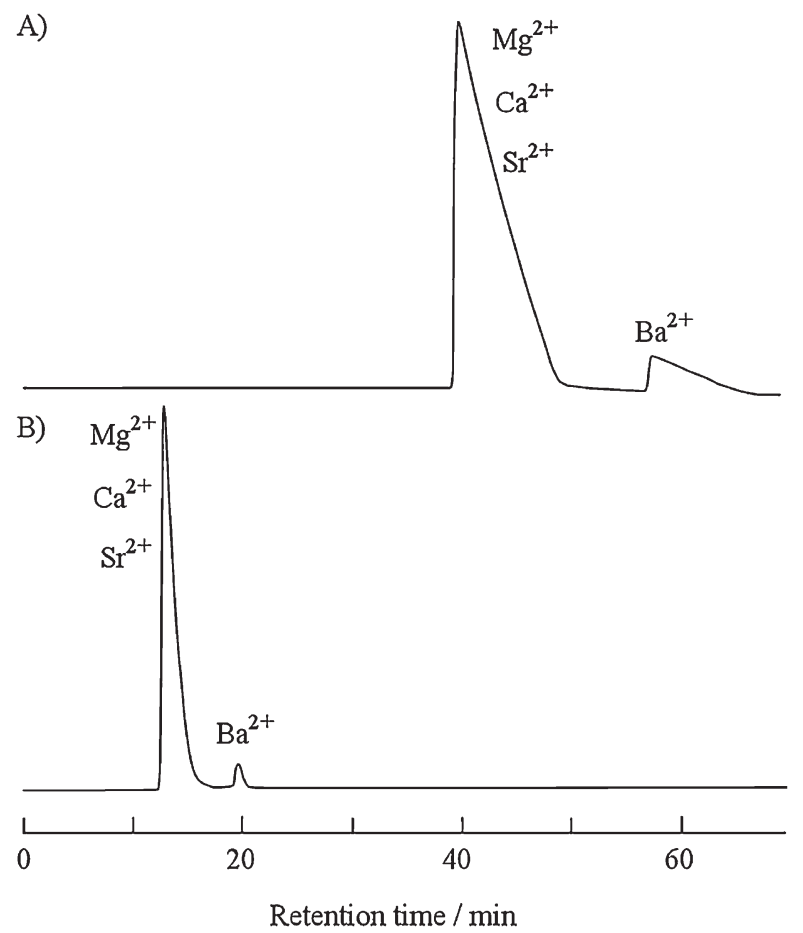

Figure 8. Chromatographic separation of alkali earth chloride on A) Si-1b and B) Si-1c. Eluent, $2.0 \mathrm{mmol} \cdot \mathrm{L}^{-1} \mathrm{HNO}_{3}$; flow rate, $1.0 \mathrm{~mL} \cdot \mathrm{min}$; sample concentration: $\mathrm{Mg}^{2+}, 10 \mathrm{ppm} ; \mathrm{Ca}^{2+}, 10 \mathrm{ppm}$; $\mathrm{Sr}^{2+}, 20 \mathrm{ppm} ; \mathrm{Ba}^{2+}, 30 \mathrm{ppm}$.

56, 6471 (1991).

5. T. Kakuchi, Y. Harada, T. Satoh, K. Yokota, and H. Hashimoto, Polymer, 35, 204 (1994).

6. T. Kakuchi, T. Satoh, S. Umeda, J. Mata, and K. Yokota, Chirality, 7, 136 (1995).

7. K. Yokota, O. Haba, T. Satoh, and T. Kakuchi, Macromol. Chem. Phys., 196, 2383 (1995).

8. T. Kakuchi, T. Satoh, J. Mata, S. Umeda, H. Hashimoto, and K. Yokota, J. Macromol. Sci., Chem., 3, 325 (1996).

9. T. Kakuchi, T. Satoh, and K. Yokota, J. Synth. Org. Chem. Jpn., 55, 290 (1997).

10. T. Satoh, D. Kitazawa, H. Hashimoto, K. Yokota, and T. Kakuchi, Macromolecules, 30, 2802 (1997).

11. T. Satoh, Y. Tanaka, K. Yokota, and T. Kakuchi, React. Funct. Polym., 37, 293 (1998).

12. T. Kakuchi, T. Hatakeyama, H. Kanai, T. Satoh, K. Yokota, K. Haraguchi, and H. Kaga, Polym. J., 31, 293 (1999).

13. I. Otsuka, R. Sakai, T. Satoh, R. Kakuchi, H. Kaga, and T. Kakuchi, J. Polym. Sci., Part A: Polym. Chem., 43, 5855 (2005).

14. T. Kakuchi, T. Satoh, H. Kanai, S. Umeda, T. Hatakeyama, and K. Yokota, Enantiomer, 2, 273 (1997).

15. S. Umeda, T. Satoh, K. Saitoh, K. Yokota, and T. Kakuchi, J. Polym. Sci., Part A: Polym. Chem., 36, 901 (1998).

16. S. Umeda, T. Satoh, K. Saitoh, H. Kanai, M. Kamada, K. Yokota, and T. Kakuchi, Enantiomer, 5, 473 (2000). 